\title{
J oão Carvalhaes, um psicólogo campeão do mundo de futebol
}

\section{J oão Carvalhaes, a psychologist world champion football}

\section{J osé Augusto Evangelho Hernandez*}

Instituto de Psicologia - Universidade do Estado do Rio de Janeiro - UERJ, Rio de Janeiro, Rio de Janeiro, Brasil

\begin{abstract}
RESUMO
Considerando que são escassas e superficiais as informações sobre J oão Carvalhaes e sua atuação pioneira na Psicologia do Esporte Brasileira, este texto procurou contribuir para a diminuição dessa lacuna. Foi identificada a origem dos conhecimentos teóricos e técnicos utilizados por esse pioneiro. Foram descritas as experiências do psicólogo com árbitros de futebol, com atletas do São Paulo Futebol Clube e da Seleção Brasileira de Futebol Campeã Mundial de 1958. Os testes aplicados pelo psicólogo na avaliação psicológica dos atletas são mencionados, bem como algumas de suas ideias acerca da Psicologia esportiva. Além disso, são comentadas suas publicações científicas (artigos e livro) e sua participação no II Congresso Internacional de Psicologia do Esporte em Washington (EUA), 1968. Na crítica ao trabalho de Carvalhaes são apontadas algumas virtudes e limitações e lançadas algumas questões, que visam provocar futuras investigações nessa área de conhecimento.
\end{abstract}

Palavras-chave: Psicologia do esporte; História da Psicologia; Avaliação psicológica.

\begin{abstract}
Considering that information about J oão Carvalhaes and his pioneering work on Brazilian Sports Psychology is scarce and superficial, this paper aimed at contributing to overcome this gap. At first, this study identified the origin of the theoretical and technical knowledge utilized by this pioneer. A description outlined the experiences of the psychologist with soccer referees as well as with athletes of São Paulo Futebol Clube and of the Brazilian Soccer Team, the 1958 World Cup Champion. Both the tests applied by the psychologist upon the psychological assessment of the athletes and some of his ideas regarding sports psychology are mentioned. Besides, comments are presented on his scientific literature (articles and book) and on his participation in the II International Sports Psychology Congress in Washington (USA) in 1968. The criticism of Carvalhaes' work points out some virtues and limitations besides launching a few questions with the purpose of provoking future investigations in the field of knowledge.
\end{abstract}

Keywords: Sport Psychology; History of Psychology; Psychological assessment. 


\section{I ntrodução}

Desde o final do século $X I X$ e início do $X X$, principalmente nos Estados Unidos da América (EUA) e na União das Repúblicas Socialistas Soviéticas (URSS), era desenvolvida a Psicologia do Esporte. Em consequência, essas duas potências mundiais concorriam para assumir o título de fundadores dessa especialidade da Psicologia. Entretanto, em torno de 1970, nos EUA, muito pouco de Psicologia aplicada ao esporte (prática) existia, predominava a pesquisa psicológica restrita aos meios acadêmicos. Weinberg e Gould (2008) registraram que, em 1966, Bruce Ogilvie, psicólogo oriundo da clínica psicológica, foi um dos primeiros que começaram o trabalho prático de assessoramento a atletas e equipes esportivas e, portanto, é considerado o pai da Psicologia aplicada ao esporte na América do Norte. Segundo Cruz (1991), desde os anos 60, influenciados pelas ideias de Alexander Puni e Peter Rudik, considerados os pais da Psicologia do Esporte soviética, os psicólogos do leste europeu se dedicaram à preparação psicológica dos desportistas para as competições. Surpreendentemente, no Brasil, em 1954, antes dos gigantes americanos e russos, João Carvalhaes começou a aplicar a Psicologia à arbitragem de futebol. Valdés Casal (2007) se revelou assombrado que isso tenha ocorrido precocemente, uma década antes do Congresso de Roma (1965), que formalizou a existência da Psicologia do Esporte no mundo. Seria este brasileiro pioneiro em intervenção psicológica na Psicologia aplicada (prática) ao esporte no mundo? É uma tese, no mínimo, instigante, que deve ser verificada de forma mais aprofundada em futuras investidas no resgate da história da Psicologia do Esporte brasileira.

Uma breve revisão da evolução da Psicologia no Brasil, a partir da década de 30, informará acerca da formação e do conhecimento de Carvalhaes. Em 1934, começa o período universitário da história da Psicologia brasileira com a criação da Universidade de São Paulo. A partir daí, a Psicologia passou a ser disciplina obrigatória nos cursos de Filosofia, Ciências Sociais, Pedagogia, e em todas as licenciaturas. Antes disso, constava apenas como disciplina opcional da Psiquiatria e da Neurologia. Foi característica dessa época, a vinda de professores estrangeiros, a formação de bibliotecas especializadas e, até, o surgimento de uma carreira profissional nessa área de conhecimento (PESSOTTI, 1988).

Além disso, é desse período o surgimento de uma série de associações e sociedades de Psicologia. A primeira delas foi a Sociedade de Psicologia de São Paulo, fundada em 1945, atualmente denominada Associação de Psicologia de São Paulo. Em 1954, surgiu a Associação Brasileira de Psicólogos. O objetivo principal dessas entidades era trabalhar para o estabelecimento da Psicologia como profissão. As primeiras propostas para a formação e regulamentação 
da profissão de psicólogo no Brasil foram publicadas no periódico Arquivo Brasileiro de Psicotécnica. Essas ideias incluíam a construção de cursos de bacharelado e licenciatura em Psicologia Educacional, Clínica e do Trabalho.

O início da psicotécnica no Brasil se deu na década de 30, momento em que houve um importante impulso para o desenvolvimento industrial do país. Com a revolução de 30, o latifúndio rural perdeu espaço para a produção industrial adotada no Estado Novo. "O Brasil precisa crescer" era o slogan oficial do período. Dentre as novas demandas do novo sistema produtivo, surgiu a necessidade da escolha adequada da força de trabalho. Até então, a mão de obra especializada era importada, o que se constituía num problema. $\mathrm{Na}$ busca de soluções, aparece a função do psicotécnico, encarregado de examinar as aptidões e o caráter dos candidatos aos postos de trabalho, bem como fornecer treinamento para qualificar e melhorar o rendimento dos trabalhadores (MARTINS, 2004).

Com o aparecimento da Psicologia Industrial, destacou-se o pioneirismo de Roberto Mange (1885-1955), engenheiro suíço que veio para o Brasil para ser professor de Mecânica Aplicada às Máquinas da Escola Politécnica de São Paulo. Seu nome, porém, inscreveu-se na História da Psicologia brasileira por seu trabalho em instrução profissional racional e seleção de pessoal com base na Psicotécnica. Foi uma das figuras mais relevantes na aplicação da Psicologia às questões do trabalho. Seus trabalhos foram determinantes para a criação do Instituto de Organização Racional do Trabalho (IDORT) de São Paulo. Mange, com outros engenheiros e educadores, foi fundador de vários centros de seleção de ferroviários, posteriormente coordenados pela Comissão de Psicotécnica da Associação Brasileira de Engenharia Ferroviária. Em 1942, Mange foi chamado para organizar e dirigir o Serviço Nacional de Aprendizagem Industrial (SENAI) de São Paulo. Nesse departamento, reuniu um importante grupo de trabalhadores da Psicologia: Ítalo Bologna, Oswaldo de Barros, Valter Barioni, Nélson Campos Pires, Joaquim Machado de Melo e Jason Ribeiro da Silva, Robert Veit e Betti Katzenstein. Também realizou extenso trabalho nas seguintes instituições: Estrada de Ferro Sorocabana, Centro Ferroviário de Ensino e Seleção Profissional, um dos centros de difusão da Psicologia Industrial, e Serviço Nacional de Aprendizagem Comercial (SENAC).

No Rio de Janeiro, foi de fundamental importância o trabalho de Emilio Mira y López no Instituto de Seleção e Orientação Profissional (ISOP) para o desenvolvimento da Psicologia aplicada ao trabalho (LOURENÇO FILHO, 1971; PENNA, 2004). Esses pioneiros da Psicologia trabalharam fora das instituições universitárias. As universidades, nos seus primeiros anos de funcionamento, primaram pela ênfase nos estudos teóricos. Há, inclusive, registros da aversão de acadêmicos à Psicologia Aplicada da época. Por exemplo, o 
trabalho de Mira y López no ISOP era, jocosamente, classificado de "mirotécnicas" na Universidade Federal do Rio de Janeiro, segundo Schneider (1992) ${ }^{1}$ apud Mancebo (1999). A formação universitária especializada em Psicologia ainda não tinha cunho profissionalizante. Somente em 1962, após o decreto lei número 4.119 de 27 de agosto de 1962, que regulamentou a profissão do psicólogo, iniciaria o período profissional da Psicologia no Brasil (PESSOTTI, 1988).

Nesse contexto, aparecem as primeiras aplicações da Psicologia ao ambiente desportivo. Como se pode observar, o que caracterizou essa fase inicial da Psicologia do desporto foi a utilização de teorias e técnicas, oriundas principalmente da Psicologia aplicada, ao mundo do trabalho. Carvalho e Jacó-Vilela (2009) registraram evidências da relação entre Psicologia e esporte ou atividade física a partir da década de 1930, encontradas nas Revistas da Escola de Educação Física do Exercito e da Escola Nacional de Educação Física e Desportos da Universidade do Brasil. Além disso, as autoras localizaram, nesse período, o trabalho da Professora Adjunta de Psicologia Aplicada na Escola Nacional de Educação Física da Universidade do Brasil, Cecília Torreão Stramandinolli, assistente do catedrático de Psicologia Aplicada, professor Carlos Sanchez Queiroz. Contudo, as informações se referem a trabalhos teóricos, publicações de artigos e atividades docentes. Não há evidências de trabalho prático e intervenção psicológica com desportistas. A continuidade dessas investigações deverá produzir novos dados sobre esse período inicial da relação entre Psicologia e Esporte no Brasil.

O primeiro registro da relação entre a Psicologia aplicada ao esporte no Brasil é de 1954. Nesse ano, João Carvalhaes foi contratado pela Federação Paulista de Futebol para trabalhar na avaliação, seleção e treinamento de árbitros de futebol. Quem era Carvalhaes, afinal? J oão Carvalhaes nasceu no dia 15 de agosto de 1917, na Estação Climática de Santa Rita do Passa Quatro, pequena cidade do interior do estado de São Paulo. Fez o curso fundamental em sua cidade natal e, na sequencia, conquistou a habilitação para o magistério na Escola Normal. Graduou-se no Bacharelado em Ciências Políticas da Escola Livre de Sociologia e Política de São Paulo. Nessa graduação, entre outras disciplinas, constavam Estatística, Psicologia Geral e Psicologia da Personalidade. Sem dúvida, estas despertaram o interesse do estudante pela área psicológica.

Em 1942, aos 25 anos de idade, Carvalhaes iniciou seu trabalho na The São Paulo Tranway Light and Power Company Limited, empresa canadense contratada pela Prefeitura de São Paulo para, entre outras tarefas, operar o transporte de passageiros em bondes elétricos. Nessa companhia, até 1946, Carvalhaes exerceu os cargos de Escriturário e Encarregado de Grupo e começou sua experiência de Seleção de Pessoal com aplicação de testes psicológicos. Em 1947, toda a administração do sistema de transporte coletivo passou para a 
prefeitura paulista e, em consequência, foi criada a Companhia Municipal de Transportes Coletivos (CMTC). Na nova empresa, Carvalhaes ocupou os cargos de Assistente Técnico da Divisão de Psicologia e Formação Profissional e Chefe da Divisão de Higiene e Segurança do Trabalho do Departamento Médico. Em sua passagem por esta divisão, implementou programas associando teatro, Psicologia e prevenção de acidentes do trabalho. Por fim, foi Psicotécnico Supervisor nas áreas de ensino, seleção e formação profissional. Em 1970, Carvalhaes encerrou sua participação como funcionário da CMTC (CARVALHAES, 1970).

Conforme depoimento do psicólogo J osé Glauco Bardella, atual diretor da Editora Vetor e colega de trabalho de Carvalhaes na CMTC, o mesmo dedicava-se ao treinamento de instrutores que, após, atuavam junto aos motoristas. Na tarefa de seleção de pessoal, o Army Test foi o teste de inteligência utilizado por Carvalhaes, instrumento que possuía duas formas: a beta, destinada a sujeitos não alfabetizados ou de baixa escolaridade e, a alfa, para os de escolaridade mais alta (CIAMPA; AZEVEDO; WAENY, 2001).

Os primeiros trinta anos do século XX caracterizaram-se como sendo a era dos testes psicológicos na Psicologia. O primeiro grande teste psicológico de sucesso, o Binet-Simon, tinha sido lançado na Europa e, em 1916, a sua famosa versão Binet-Stanford, nos EUA. Contudo, havia a necessidade da criação de um teste de inteligência que pudesse ser aplicado coletivamente. A versão original do Army Test foi desenvolvida para o exército norte-americano durante a Primeira Guerra Mundial para avaliar a habilidade intelectual de recrutas. Uma comissão de psicólogos liderada por Robert Yerkes, então presidente da American Psychological Association, foi responsável pela criação do teste. Este instrumento inaugurou, na Psicometria, a modalidade dos testes coletivos. Até então, os testes psicológicos eram feitos para aplicação individual. No entanto, com a evolução da Psicometria, outros sistemas de avaliação da inteligência foram criados superando o Army Test (URBINA, 2007).

A forma beta deste instrumento foi padronizada no Brasil para a Estrada de Ferro Sorocabana e, depois, por Osvaldo de Barros Santos para o Serviço Nacional de Aprendizagem Industrial (SENAI). Parte dos conhecimentos psicológicos de Carvalhaes provinha de suas relações com esses profissionais que aplicavam testes psicológicos na área dos transportes e da indústria.

Aprendemos na Escola de Sociologia e Política de São Paulo, através do então professor Dr. Roberto Mange a usar os meios mais eficientes de analisar os pormenores de um trabalho, relacionar as exigências e as medidas de classificação dos candidatos para o exercício de cada atividade (CARVALHAES, 1974, p. 125). 
Além disso, em 1951, Carvalhaes frequentou o curso de aperfeiçoamento do Centro de Estudos Franco da Rocha sobre Psicodiagnóstico Miocinético (PMK), de Mira y López; em 1952, participou dos cursos oferecidos pela Sociedade de Psicologia de São Paulo também sobre o PMK, proferido por Hernani Borges Carneiro; e, em 1953, do curso sobre Modernas Teorias da Personalidade, ministrado por Carolina Martuscelli Bori (COSTA, 2006; WAENY, AZEVEDO, 2003). Isso explicaria, em grande parte, a origem dos conhecimentos psicológicos de João Carvalhaes e sua formação em Psicologia.

O professor Carvalhaes, como costumava ser chamado, teve participação ativa nos movimentos que aconteceram no Rio de J aneiro e em São Paulo para a regularização da Psicologia no Brasil. Inclusive, no período de 1951-52, foi sócio efetivo e segundosecretário da então denominada Sociedade de Psicologia de São Paulo.

Como visto, a primeira associação de Carvalhaes com a Psicologia se dá no âmbito do Trabalho, haja vista as diversas publicações e palestras que realizou nesta área, além de sua prática profissional na CMTC. Vários foram os temas abordados, Carvalhaes (1946) discorreu sobre o uso da Psicologia e dos estudos sobre a personalidade para a contratação de funcionários. O método proposto pelo autor permitiria contratar as pessoas mais adequadas para cada função. Carvalhaes, que era sócio técnico da Associação Paulista dos Técnicos de Higiene e Segurança do Trabalho, proferiu uma palestra na Associação Brasileira para Prevenção de Acidentes relacionando fatores psicológicos de trabalhadores com a produtividade dos mesmos. Em artigo sobre o tema (CARVALHAES, 1960), alertou para a complexidade do problema psicológico na produção e apelou aos empregadores para que utilizem as ciências aplicadas ao trabalho no ajustamento dessa questão.

Ficou evidente, também, o interesse do autor pela pesquisa científica associada à criação de instrumentos de medida para o desenvolvimento de suas atividades de avaliação psicológica na seleção de pessoal. Carvalhaes (1955) relatou um estudo baseado em pesquisas sobre a coordenação motora de operadores de máquinas. Essas investigações mostraram que os aspectos motores envolvidos nessa atividade não são tão simples quanto aqueles dos tecelões e caixas bancários. Em consequência disso, o pesquisador construiu um novo teste para a seleção de operadores de máquinas o Teste Sinal - usando movimentos mais complexos do que aqueles dos Testes Tapping e Pontilhagem do Teste de Aptidão Mecânica de Leon Walther. O Teste Sinal destinava-se a seleção de pessoal para tarefas que exigiam movimentação e coordenação não só do antebraço, mas também de todos os dedos e, além disso, fornecia uma medida de fadiga muscular. Observa-se, nesse ponto, 0 
interesse do psicometrista pela coordenação motora, tema que, mais tarde, seria retomado com atletas de futebol. O Ministério de Educação e Cultura, na época, reconhecendo as habilidades de Carvalhaes como psicometrista, solicitou a colaboração do mesmo na composição de um arquivo de testes da Campanha de Inquéritos e Levantamento de Ensino Médio e Elementar (COSTA, 2006).

O Teste de Destreza Digital criado por Carvalhes (1970) foi publicado, entretanto, no momento em que o presente texto foi escrito, ainda não constava da lista de instrumentos psicológicos homologados pelo Sistema de Avaliação de Testes Psicológicos do Conselho Federal de Psicologia, órgão que controla a qualidade dos testes psicológicos no Brasil na atualidade.

\section{Carvalhaes e o esporte}

Tudo indica que a relação de João Carvalhaes com o esporte se deu através da modalidade boxe. Concomitante ao exercício de Psicologia do Trabalho o mesmo atuava como comentarista de boxe, escrevendo para jornais sob o pseudônimo João do Ringue. Segundo seu filho João Francisco Carvalhaes, "Ele se envolveu no esporte através de lutas de boxe, que ele ia lá como radialista, comentarista, qualquer coisa assim" (CIAMPA; AZEVEDO; WAENY, 2001). Carvalhaes possuía registro como jornalista profissional, conforme sua Carteira de Trabalho. Uma evidência de sua atuação como jornalista licenciado em Psicologia é o artigo intitulado "Resultado do Método Introspectivo", publicado no Jornal da Cidade de Taquaritinga, em 1944. Dezenas de artigos de sua autoria abordando a relação boxe e Psicologia foram publicados no período de 1952 a 1957, principalmente no jornal Equipe. Em 1954, esse trabalho na imprensa teria motivado o convite para selecionar e treinar os árbitros de futebol da Federação Paulista de Futebol. Esta data é o marco histórico do início da Psicologia do Esporte no Brasil. O próprio Carvalhaes (1974, p. 15) revelou que:

\footnotetext{
A oportunidade que se nos ofereceu foi dada pelo Dr. Ary Silva então diretor da Escola de Árbitros da Federação Paulista de Futebol, e foi suficiente para estudarmos e reformularmos o processo de admissão dos candidatos e de ensino nessa entidade.
}

Através de entrevistas e observação do trabalho dos árbitros mais experientes, Carvalhaes identificou um conjunto de aptidões que estariam relacionadas com as tarefas do árbitro dentro do campo de futebol: personalidade, nível mental, visão estereoscópica, estimativa da velocidade relativa, noção de espaço, tempo de reação, reação 
psicomotora (estímulo auditivo), tempo médio de reação (estímulos visuais e auditivos) e atenção. "A inferência a que chegamos sobre os traços de personalidade e as aptidões em geral de um árbitro de futebol nos pareceram lógicas em se tratando de resultados de análise das suas tarefas" (CARVALHAES, 1974, p. 16). Nas dependências da Federação foi montado um laboratório composto por dez aparelhos que mediam essas aptidões requeridas na arbitragem, atividade que se estendeu até 1959.

Através dos dados que coletava, utilizando estatísticas descritivas, Carvalhaes (1974) determinava alguns pontos de corte nas medidas que serviam de "padrões de classificação" para os árbitros avaliados. Por exemplo, no resultado do estudo de avaliação do tempo de reação psicomotora ficou estabelecido que candidatos que apresentassem valores acima de 50 centésimos de segundo, provavelmente, não teriam condições para exercer com sucesso a atividade de árbitro. Embora a investigação com os árbitros esportivos tenha começado de forma criteriosa e promissora, essa linha de pesquisa não prosperou. Contraditoriamente, a Psicologia dos árbitros é uma das áreas menos exploradas e mais carentes de conhecimentos científicos e técnicas de intervenção. Isso é evidenciado pelos poucos livros e estudos encontrados sobre 0 assunto no âmbito nacional e internacional (CÁRDENAS, 2007). Segundo Silva (2009), a preparação psicológica pode ser considerada uma das maiores lacunas nos cursos de formação de novos árbitros no Brasil. Não obstante, Weinberg e Richardson (1990) afirmaram que, dentre os fatores envolvidos na arbitragem esportiva internacional, os psicológicos parecem ser os mais críticos.

Com a divulgação do trabalho realizado com os árbitros da Federação Paulista, Carvalhaes foi contratado, em 1957, para aplicar a Psicologia nos atletas do São Paulo Futebol Clube (SPFC). O mesmo declarou que este foi o fato mais significativo de sua vida profissional. O então Supervisor de Futebol do Clube, José Teixeira, justificou essa contratação, explicando o seu interesse na atividade do psicólogo.

O importante é que o jogador chegue primeiro. Mas prá ele chegar primeiro, ele tem que sair primeiro que o adversário. Prá ele sair primeiro, ele tem que pensar primeiro, prá ele pensar primeiro, ele tem que ter um estímulo ou visual [...] ou seja, o que for [...] e sair rápido. Então esse estímulo, ele tem que estar condicionado e esse tempo de reação fez com que eu desse um valor muito grande ao treinamento. Não é a velocidade pura e sim a saída rápida. Quer dizer, eu me preocupei muito com o tempo de reação. E esse era o trabalho que o professor Carvalhaes fazia (CIAMPA; AZEVEDO; WAENY, 2001). 
Entre as técnicas de avaliação utilizadas com os jogadores do SPFC, foi usado o Army Teste, forma beta, revisado para uso civil por Kellogg e Morton (1934). Este instrumento mede um fator g, isto é, inteligência geral não específica, constituído por seis subtestes: Labirintos, Símbolos, Reconhecimento de Erros, Formas, Figuras Incompletas e Avaliação de Diferenças. Além da obtenção de resultados por subteste, era calculado um resultado global, transformado num valor de quociente de inteligência (QI). Os resultados dos testes eram divididos em cinco classificações: muito superior; superior; médio, Inferior, muito inferior. Carvalhaes estava criando sua própria tecnologia para a intervenção no futebol. O psicólogo detinha conhecimentos sobre estatística e, embora não fosse um acadêmico, buscava o rigor científico em seus procedimentos de investigação. Realizou uma pesquisa em que comparou os escores médios de inteligência de vários grupos profissionais (mecânicos, eletricistas, auxiliares de escritório, ajudantes de artífice, mensageiros, motoristas e cobradores de ônibus) com os escores médios de 67 jogadores de futebol. Através da análise do gráfico de distribuição de frequência (profissões por escores médios no teste), o pesquisador concluiu que a atividade futebolística, comparada com outras profissões, exigia uma boa quantia de inteligência. Contudo, demonstrou ponderação com relação aos resultados obtidos e sugeriu:

\begin{abstract}
Faz-se mister agora planejar outra pesquisa, usando uma prova específica de inteligência que envolva uma qualidade geral com características sensomotriz, conforme já foi preconizado por outros estudiosos do assunto. Os resultados dessas pesquisas poderão ser correlacionados com 0 rendimento do atleta. Assim chegar-se-á à possível conclusão de que, para a seleção inicial de atletas das categorias infantil e juvenil, deverá ser exigido, além de aprovação da conduta e eficiência em campo, um resultado em nível satisfatório do teste preconizado (CARVALHAES, 1971, p. 100).
\end{abstract}

Logo que passou a atuar no SPFC, Carvalhaes teria feito uma indicação de "corte" e de escalação para o técnico do time Bela Gutman. Nota-se, nessa passagem, a presença do viés do psicólogo do trabalho que, através da avaliação psicológica, sugere o homem mais adequado para o cargo. A sugestão teria sido aceita pelo treinador e foi seguida de um resultado de sucesso: o título de campeão paulista de 1957. Essa experiência foi descrita pelo então Diretor do Departamento de Futebol do clube Manoel Raimundo Paes de Almeida:

Inclusive, na partida decisiva do título em 1957, teve influência na sorte do encontro, dizendo ao técnico Bela 
Gutman que determinado valor não reunia condições psicológicas para um tão importante acontecimento. O São Paulo venceu e o valor apontado como 'melhor' por João Carvalhaes disputou uma grande partida (PAES DE ALMEIDA, 1974, p. 11).

\section{Carvalhaes e a Seleção Brasileira de Futebol}

Após as derrotas na Copa do Mundo de Futebol de 1950 para o Uruguai (em pleno Maracanã) e de 1954 para a Hungria, os atletas brasileiros foram acusados de jogar sem fibra. Os jogadores negros eram os que mais sofriam com essas acusações. Segundo Assaf (2001), a France Football, prestigiosa revista francesa, avaliou todas as equipes de futebol que se preparavam para disputar a Copa da Suécia de 1958 e classificou a seleção brasileira apenas no sexto lugar. Nessa avaliação, os jogadores brasileiros foram considerados como excessivamente temperamentais, imaturos, emocionalmente vulneráveis e, portanto, despreparados psicologicamente para uma competição do porte do Campeonato Mundial de Futebol.

Lepiani (1958) descreveu o clima pesado que envolveu os atletas brasileiros entre 1950 e 1958. Diz este jornalista que foram 2.905 dias de cabeça baixa, ombros curvados e "rabo entre as pernas". Parece que o jogador brasileiro temia defrontar-se com sua própria identidade, pois acreditava que a derrota de 1950 revelara sua fraqueza, sua covardia e sua inferioridade. Sentimento que o famoso jornalista e dramaturgo Nelson Rodrigues definira como "complexo de vira-latas".

Frente a esse contexto negativo, João Havelange, recém-eleito presidente da Confederação Brasileira de Desportos (CBD), em 1958, confiou ao seu vice, Paulo Machado de Carvalho, empresário paulista de grande sucesso, a chefia da delegação responsável pelo selecionado nacional. No plano de trabalho elaborado por este, um psicólogo estava incluído na comissão técnica da Seleção Brasileira de Futebol. Assim, foi convocado João Carvalhaes, campeão paulista pelo SPFC no ano anterior (SARMENTO, 2006). Sobre essa convocação, comentou Carvalhaes (1974, p. 28): “Lembramo-nos muito bem do convite, recebido de Vicente Feola, solicitando nosso comparecimento à Guanabara para expor nossas ideias à comissão técnica."

Carvalhaes (1974) relatou que, na preparação para a Copa de 1958, ainda no Rio de Janeiro, foi aplicado o teste de inteligência (Army Test) nos atletas selecionados pelo técnico Feola. O mesmo foi imediatamente corrigido, os escores submetidos à estatística e os resultados apurados. Numa reunião com a comissão técnica, esses resultados foram apresentados, os escores dos jogadores foram 
comparados. Houve um inexplicável vazamento das informações e uma avalanche de especulações na imprensa sobre possíveis indicações de cortes de atletas propostos pelo psicólogo baseado nas avaliações. De todas, a mais crítica e que se tornou o ponto crucial dessa polêmica, foi a do jogador Garrincha.

\begin{abstract}
Acreditamos ter dado a entender que a pessoa menos inteligente provavelmente não seria capaz de executar, comparativamente a outra mais inteligente, muitas tarefas a uma só vez, para depois encontrar as respectivas soluções. Sem saber exatamente por que, essa passagem ficou marcada e, por mais explicações que viessem a ser dadas, classificaram-nos de maneira ridícula como incompetente, face à produção exuberante de um determinado atleta, cujo resultado do teste de inteligência havia acusado um nível baixo (CARVALHAES, 1974, p. 29).
\end{abstract}

Antes de partir para a Suécia, a Seleção concentrou-se em Poços de Caldas/MG e, nessa cidade, os testes de personalidade PMK e Figura Humana foram aplicados. O PMK é uma técnica projetiva criada pelo médico e psicólogo Mira y López (1939), atualmente considerado bom para o uso profissional pelo Serviço de Avaliação de Testes Psicológicos do Conselho Federal de Psicologia e utilizado na avaliação psicológica em diversas áreas de atividade. Esta técnica consiste da análise de traços e desenhos (linhas, círculos, "ziguezagues" e retas paralelas) feitos com lápis para a avaliação de aspectos da personalidade. $O$ nome do teste, Psicodiagnóstico Miocinético, indica claramente que se trata de uma prova psicomotora baseada na relação do controle dos músculos com os movimentos (MIRA, 1987).

\footnotetext{
O plano nessa área de pesquisa era possuir a primeira amostra das condições psicológicas dos atletas através desses testes em uma situação que não era competitiva. Essa prova de expressão gráfica compõe-se de vários subtestes, entre eles, os lineogramas, que também foram usados na Seleção Brasileira. A fundamentação do teste está na chamada teoria motriz da consciência, de acordo com a qual, toda intenção ou propósito de reação se acompanha de modificação no tônus postural (CARVALHAES, 1974, p. 32).
}

O trabalho de avaliação teve continuidade durante toda a Copa, na concentração da cidade de Hindas, Suécia. Aí foram realizadas as aplicações dos lineogramas, subteste do PMK, em todos os atletas, bem como foram repetidas em todos os jogos, até o jogo final. Carvalhaes (1974, p. 34) procurou explicar seus objetivos, "nesses momentos procurávamos conforme os resultados e as alterações verificadas no teste, fixar um tipo de orientação, um aconselhamento de suporte ou de apoio ao atleta." 
Em torno da polêmica da avaliação psicológica dos atletas, muita informação de todas as qualidades foram e continuam sendo divulgadas na imprensa brasileira. O jornalista Fernandes (2009, sem página) escreveu:

De cara, Carvalhaes quis porque quis aplicar os psico-testes nos jogadores, entre os quais estavam Pelé, com 17 anos, e Mané Garrincha, com 25. Certo dia, Carvalhaes chamou Garrincha para o exame. Ao preencher a ficha no espaço destinado à profissão, o ponta pisou na bola: "Atreta". Nos exercícios seguintes, não foi muito melhor, conseguindo 38 pontos em 123 possíveis. Em seu relatório, o psicólogo jogou duro: instrução primária, inteligência abaixo da média e agressividade zero.

Conforme relata Piza (2008), em entrevista concedida pela comemoração dos 50 anos do primeiro campeonato mundial, Pelé declarou que sentia-se em boas condições físicas e psicológicas para o jogo da estréia com a Áustria, em 8 de junho de 1958. João Carvalhaes era o único que acreditava que ele e Garrincha não tinham condições de assumir as responsabilidades que envolviam essa competição. "Eu estava pronto, sim. Não sei se preferiram esperar um pouco por eu ser jovem. O psicólogo, Dr. Carvalhaes, havia dito que eu e Garrincha éramos muito jovens, porque a gente vivia fazendo brincadeira, molecagem". Pelé tinha apenas 17 anos de idade, realmente era muito jovem.

Com relação a Garrincha, Lima e Amorim (2006) relembraram que, num jogo preparatório para a copa de 1958 entre a seleção brasileira e o A. C. Milan (Itália), Garrincha driblou toda a defesa adversária e poderia "entrar com bola e tudo". Mas, para surpresa, manteve a bola em cima da linha do gol e esperou que um dos zagueiros retornasse para, novamente, driblá-lo e, finalmente, fazer o gol. Referindo-se ao comportamento geral do atleta, Gilmar, goleiro da seleção campeã, comentou:

Se você fosse ver o laudo intelectual do Garrincha, ele não podia participar de nada mesmo. Ele não tinha, realmente, assim essa condição. Era uma pessoa bem simplória, quer dizer, era uma criança adulta, você entendeu? Era um homem com mentalidade de criança, Ele não se preocupava com nada: ele não queria saber se tinha jogo, se não tinha jogo, quem ia marcar [...] Então, na hora da preleção, a gente dizia: olha, com o Garrincha não precisa falar, deixa ele fazer o que sabe, que ele sabe o que vai fazer. E quando ele entrava dentro de campo, ele se transformava (CIAMPA; AZEVEDO; WAENY, 2001).

O fato de Pelé e Garrincha não terem jogado nos dois jogos iniciais da Copa de 1958 pode estar relacionado às expectativas acerca das 
características psicológicas dos jogadores brasileiros, geradas após as derrotas de 1950 e 1954. Segundo Assaf (2001), os jogadores negros eram os mais atingidos com isso. Sabe-se que, nas origens do futebol brasileiro, há uma história repleta de preconceito e discriminação racial (MÁRIO FILHO, 2003). Coincidentemente, o time brasileiro que estreou nos gramados suecos em 1958 tinha apenas um negro, Didi, na realidade, mulato, quase branco. Os jogadores negros estavam todos na reserva, inclusive Pelé e Garrincha. Nessa perspectiva, o preconceito racial teria escalado o time e não os testes de Carvalhaes. Evidentemente, essa é uma tese interessante que imprescinde de uma investigação complexa e específica.

Os testes aplicados por Carvalhaes, na seleção brasileira, podem não ter sido eficazes para o exercício do futebol. Reside aí o equívoco do psicólogo. Mas, certamente, foram efetivos para indicar a fragilidade psicológica do homem Garrincha, haja vista que este morreu precocemente de cirrose hepática e em péssimas condições psicológicas, ponderou Cozac (2008). Apesar disso, muitas vezes, os escritos têm alcançado o nível de desqualificação pessoal dos profissionais envolvidos. Dienstmann e Denardim ( $s / d, \quad p .43$ ) descreveram a comissão técnica da seleção:

E havia um dentista, Mário Trigo, cuja missão principal era contar piadas, e até um psicólogo, João Carvalhaes. Ele considerava o atacante Garrincha mentalmente incapaz, e a presença do psicólogo na Seleção Brasileira numa Copa foi abandonada - em especial depois que descobriram que Carvalhaes era, estranhamente, um grande supersticioso.

Em nenhum momento, na revisão de seus escritos (artigos e livro) e na descrição de suas práticas, denota-se qualquer evidencia de pensamentos supersticiosos na mente do pioneiro da Psicologia esportiva no Brasil. Pelo contrário, na leitura da sua obra, está invariável e claramente explícito o seu compromisso com a ciência e a racionalidade. Pode-se observar a lucidez do psicólogo quando manifesta sua visão sobre o ambiente desportivo:

Inicialmente, foi dito que, por força das obrigações funcionais de todos aqueles que trabalham no esporte, deixam eles de detectar outros problemas paralelos àqueles que enfrentam no dia-a-dia. Não havendo equações a resolver, os casos inexplicáveis são sempre transferidos e novamente notados em outra ocasião. O assunto volta à baila e o tempo passa. As soluções também não são estudadas e tais fenômenos ficam enquadrados nas expressões sorte, azar, se Deus ajudar, e outras inúmeras formas de justificações que chegam ao limite do absurdo. O demérito pessoal se faz presente normalmente sem que o sujeito atuante tenha consciência dessa própria desvalorização. Enquanto isso acontece, a realidade exige explicações e os atletas 
continuam totalmente bloqueados pela influência dos estereótipos (CARVALHAES, 1974, p. 46).

No retorno da Seleção Brasileira campeã do mundo ao Brasil, teria desaparecido da bagagem todo o material psicológico coletado por Carvalhaes. O mesmo teria ficado muito chateado e reclamado ao chefe da delegação. Algum tempo depois, o material reapareceria sem, contudo, nenhuma explicação com relação ao seu desaparecimento. O goleiro Gilmar, indagado sobre o episódio, disse:

\begin{abstract}
Existem certas coisas no futebol que é difícil a gente explicar [...] por exemplo, talvez ciumeira [...] porque muita gente podia pensar que este profissional tivesse querendo tomar o lugar de alguém dentro de uma comissão técnica [...] e isso existe $[\ldots]$ a gente sabe que existe. Porque que o treinador, às vezes, não quer um auxiliar com ele? Por que ele tem medo que o sujeito comece a boicotá-lo e [...] tente pegar o lugar dele. E assim é um massagista [...] é um médico [...] é uma série de problemas [...] Não posso afirmar que essa seja a realidade [...] (CIAMPA; AZEVEDO; WAENY, 2001).
\end{abstract}

Por solicitação da Federação Paulista de Pugilismo e com a autorização do SPFC, o professor Carvalhaes atuou na preparação psicológica dos lutadores para os Jogos Pan-americanos de 1963. Na oportunidade, o então jornalista e presidente da Federação, Newton Campos, reconheceu o trabalho do psicólogo mediante os seguintes comentários:

\footnotetext{
O trabalho de ordem psicológica, tão abandonado em outras oportunidades, desta feita era um dos pontos primordiais a ser atacado. Vários testes foram estabelecidos aos pugilistas. Cada um tinha o seu cadastro. Em pouco tempo o labor do professor João Carvalhaes surtia o melhor efeito. Da inibição passamos à personalidade, do retraimento atingimos a fase da elevação moral [...]. Eliminando os problemas psicológicos, colocando os nossos praticantes do pugilismo em perfeitas condições físicas, chegamos a resultados surpreendentes (CARVALHAES, 1974, p. 167).
}

Considerando a experiência de Carvalhaes, a psicóloga Kátia Rúbio comentou: "A grande virtude de Carvalhaes foi que ele não buscou nem na Rússia, nem nos Estados Unidos, quer dizer, ele fez uma Psicologia do Esporte na década de 50 sobre aquilo que se fazia de Psicologia no Brasil na década de 50." (CIAMPA; AZEVEDO; WAENY, 2001).

Depois de 50 anos de experiências de pesquisas e intervenções em Psicologia do Esporte, sabe-se que testes psicológicos não devem ser utilizados para selecionar a equipe. Weinberg e Gould (2008, p. 56) recomendaram que qualquer teste psicológico deve ser considerado 
junto com outras medidas, tais como, desempenho físico, avaliações do técnico e níveis reais de jogo. "Empregar apenas inventários de personalidade para selecionar atletas para um time ou para cortá-los de um time é um abuso de testagem que não deve ser tolerado." Becker J r. (2000), atribuiu as dificuldades enfrentadas por Carvalhaes à inadequação dos instrumentos para utilização no esporte e, principalmente, à inexperiência do psicólogo no ambiente futebolístico.

Entretanto, a atividade inicial de Carvalhaes como psicotécnico consistia na avaliação de candidatos para o exercício de diversas funções no mundo do trabalho e à emissão de pareceres aconselhando as contratações dos mesmos ou não. No seu trabalho na Escola de Árbitros da Federação Paulista de Futebol, reproduz os mesmos procedimentos. Quando passou a atuar no SPFC, da mesma forma, Carvalhaes teria feito indicação de "corte" e de escalação que foi seguida de sucesso. Essa experiência, que foi descrita por Paes de Almeida (1974), pode ter dado a convicção e segurança para Carvalhaes e para os dirigentes da Seleção de 58 para que os mesmos procedimentos fossem utilizados. Sua convocação para a seleção também foi consequência desse retrospecto.

Por outro lado, Carvalhaes não "errou" sozinho. Nos EUA, os estudos sobre a personalidade dos atletas baseados em testes psicológicos, de papel e lápis, em geral só declinariam depois, a partir de 1975, "por causa das críticas recebidas sobre sua validade preditiva e os problemas teóricos e metodológicos não resolvidos" (VALDÉS CASAL, 2007).

\section{Carvalhaes e a comunidade científica internacional}

No ano de 1965, em Roma, Itália, foi criada a primeira Sociedade Internacional de Psicologia do Esporte e realizado o I Congresso Internacional de Psicologia do Esporte. O presidente eleito foi 0 psiquiatra italiano Ferruccio Antonelli, principal responsável por estas iniciativas. Nesse evento participou o psicólogo brasileiro Athayde Ribeiro da Silva, que assessorou a Seleção Brasileira Bicampeã de Futebol na Copa Mundial de 1962. Este psicólogo carioca, membro do ISOP/FGV, foi eleito membro do Conselho da entidade, dado o prestígio da Psicologia do Esporte brasileira na época (MORRIS; HACKFORT; LIDOR, 1998).

Ribeiro da Silva (1968) ficou impressionado com a atenção que recebeu de psicólogos de vários países europeus. No I Congresso Internacional de Psicologia do Esporte participaram 450 pessoas de 33 países, no entanto, no discurso de abertura proferido por Antonelli, foi destacado nominalmente o Brasil por sua prática de Psicologia esportiva. O psicólogo comentou que foi bastante 
assediado pelos colegas europeus e norte-americanos que queriam saber acerca da prática da Psicologia esportiva brasileira. Isso o levou a pensar que o Brasil é o país pioneiro na aplicação da Psicologia ao esporte, no mínimo, na modalidade futebol. "Nossa experiência data de 1954, ocasião em que os juízes foram submetidos a testes" argumentou Ribeiro da Silva (1965, p. 67). Apesar de reconhecer a importância da data para a Psicologia do Esporte brasileira, é curioso, que $o$ autor não mencione o nome de Carvalhaes, aliás, fato que se repete em suas obras (MIRA Y LOPES; RIBEIRO DA SILVA, 1964; RIBEIRO DA SILVA, 1965; RIBEIRO DA SILVA, 1967; RIBEIRO DA SILVA, 1968). Isso será reflexo da tradicional competição entre Rio e São Paulo?

No II Congresso Internacional de Psicologia do Esporte em 1968, Washington (EUA), participou, também, Carvalhaes. Nessa oportunidade, o mesmo tornou-se sócio da Sociedade Internacional. Carvalhaes (1969) apresentou um trabalho da correlação entre o estado psicológico e o rendimento do atleta de futebol, em que defende a possibilidade de, através de instrumentos de medição psicológica (lineogramas do PMK), prognosticar o rendimento do atleta. Como consequência do acúmulo de conhecimentos das experiências e observações realizadas no período de 1957 a 1962, Carvalhaes fundamentou seu trabalho com a exposição de materiais e métodos de investigação seguida da descrição da avaliação do rendimento dos atletas. Esta avaliação foi construída através do método de notas e método do registro das participações (todos criteriosamente descritos). Além disso, o psicólogo apresentou a teoria do teste PMK e os procedimentos de obtenção e análise dos dados, mediante Coeficiente de Correlação de Pearson, Phi e Teste do Quiquadrado.

Dados todos os descontos necessários (o idealismo, por vezes, romântico de Carvalhaes, por exemplo), considerando todas as limitações teóricas e instrumentais que esta área do conhecimento tinha (que não era exclusividade do Brasil), raramente alguém fez uma tentativa tão decidida (talvez, ingenuamente pretensiosa) unindo pesquisa científica e prática em Psicologia do Esporte. Deve-se lembrar que Carvalhaes nunca foi um pesquisador acadêmico, no entanto, buscava articular a ciência e a prática da Psicologia.

Muitos são os depoimentos de familiares, amigos e conhecidos acerca das inúmeras correspondências, em diversas línguas, que o professor Carvalhaes recebia do exterior. Alguns desses testemunhos chegam a afirmar que o mesmo foi muito mais valorizado fora do Brasil (CIAMPA; AZEVEDO; WAENY, 2001).

\section{A evolução do trabalho de Carvalhaes}


O trabalho de Carvalhaes estendeu-se consideravelmente e é possível que, até hoje, nenhum psicólogo brasileiro tenha ficado tanto tempo trabalhando em um único clube, numa mesma modalidade esportiva. O professor ficou 17 anos no SPFC e, nesse tempo, como era de se esperar, seu trabalho evoluiu. Carvalhaes (1974) relatou suas experimentações com o tempo de reação dos atletas mediante a utilização de um cronógrafo, aparelho de orientação psicofísica. $\mathrm{Na}$ continuidade, foi incorporado ao seu trabalho o aconselhamento psicológico individual, baseado no método do humanista Carl Rogers, uma técnica completamente diversa da testagem psicológica, dando maior abrangência à sua intervenção. Nesse ponto, já estamos diante de um psicólogo significativamente diferente daquele de 1958. Na verdade, é mais lembrado o Carvalhaes da década de 50, obviamente devido a sua atuação na Seleção e à polêmica envolvendo o jogador Garrincha.

Outra mudança importante, no seu trabalho, foi a passagem das abordagens técnicas individuais para as grupais.

\begin{abstract}
Até o ano de 1967, dez anos após o nosso ingresso no futebol, adotamos o processo do aconselhamento individual. [...] pudemos perceber que o nosso amadurecimento profissional, então específico, havia alcançado um ótimo nível para mudar a orientação normal e de rotina. Passamos, então para a técnica de sensibilização grupal (CARVALHAES, 1974, p. 98).
\end{abstract}

Na continuidade do trabalho com a dinâmica de grupo, Carvalhaes (1971, p. 75) adotou a Sociometria de Moreno. "O teste de J. L. Moreno nos permitiu conhecer a natureza do grupo de atletas, sua estrutura, rejeições e preferências antes e depois do campeonato paulista de 1969." Além disso, Carvalhaes desenvolveu estudos comparativos entre atletas amadores e profissionais de futebol, a comunicação no esporte, entre outros.

No dia 25 de janeiro de 1974, o professor despediu-se do SPFC e encerrou sua carreira como psicólogo do esporte com a mesma simplicidade e humildade que sempre transpareceu em seus escritos. "Mais aprendi do que ensinei a vocês, atletas, razão primeira do meu trabalho no São Paulo Futebol Clube. Mais ganhei com vocês, dirigentes, técnicos médicos e professores de Educação Física do que pude oferecer." (CARVALHAES, 1974, p. 171).

Mediante a apresentação de documentos comprobatórios de sua atuação profissional como psicólogo desportivo que obteve com amigos, colegas de trabalho e representantes de entidades, 0 trabalho do professor Carvalhaes foi reconhecido e enquadrado na lei no 4119 de 27 de agosto de 1962 do Conselho Federal de Psicologia. Assim, obteve oficialmente o título de psicólogo mediante o registro do Conselho Regional de Psicologia de São Paulo. Prematuramente, 
faleceu no dia 31 de março de 1976 aos 59 anos de idade. A Academia Paulista de Psicologia, como reconhecimento ao trabalho prestado pelo psicólogo, escolheu-o Patrono da Cadeira 22, atualmente ocupada por Lino de Macedo. Em maio de 2000, a Comissão de Psicologia do Esporte do Conselho Regional de São Paulo fez uma homenagem a João Carvalhaes através de um vídeo documentário criado por Ciampa, Azevedo e Waeny (2001).

As fontes consultadas para a construção desta revisão bibliográfica foram, basicamente, os artigos publicados por João Carvalhaes nos Arquivos Brasileiros de Psicotécnica (posteriormente denominados Arquivos Brasileiros de Psicologia Aplicada), e em seu único livro, "Um Psicólogo no Futebol: Relatos e Pesquisas", de 1974. Foram revisadas, também, as poucas obras (livros e artigos) dos estudiosos da Psicologia do Esporte brasileira das últimas cinco décadas que abordaram a história da área. Evidência dessa escassez foi a busca no sistema Scielo, que não encontrou publicação sobre o tema. Também foram usados, por conveniência, alguns artigos da revista eletrônica Mnemosine, de autoria de importantes pesquisadores da História da Psicologia no Brasil, com o objetivo de contextualizar a prática de Carvalhaes. Na mesma perspectiva, foram consultados os relatos históricos dos psicólogos norte-americanos Weinberg e Gould (2008) e do espanhol Cruz (1991) com o objetivo de traçar um paralelo entre o desenvolvimento das psicologias esportivas brasileira e internacional. Os depoimentos de diversos contemporâneos de Carvalhaes, contidos no vídeo de autoria de Ciampa, Azevedo e Waeny (2001), contribuíram com dados importantes. O autor considera o presente estudo um piloto para a realização futura de uma pesquisa sobre a História da Psicologia do Esporte no Brasil.

\section{Considerações finais}

Os escassos registros produzidos pelos estudiosos da Psicologia do Esporte Brasileira sobre João Carvalhaes têm sido apresentados no formato de artigo de livro e de periódico, em geral, como parte de uma breve história geral da Psicologia do Esporte no Brasil (por exemplo, BECKER JR, 2000, 2006; COSTA, 2006; RÚBIO, 1992; 2000; 2002; 2007; SAMUSLKI, 2002; VALDÉS CASAL, 2007). Não é exagero afirmar que estes, na maioria, não vão além de alguns parágrafos. Além disso, se limitam a trazer uma descrição cronológica de fatos sem apresentarem maiores questionamentos ou reflexões críticas sobre os mesmos. No entanto, o trabalho de J oão Carvalhaes foi consideravelmente extenso, de 1954-74. Ele produziu vários artigos e um livro em que relatou intensa prática psicológica e onde deixou transparecer suas dificuldades, seus conflitos, seus sentimentos e as suas mágoas com o mundo esportivo. Até 0 
momento, não há nenhuma obra que apresente, de forma abrangente, a experiência de João Carvalhaes, trazendo à tona o significado da mesma. O vídeo produzido pelo Conselho Regional de Psicologia de São Paulo (ClAMPA; AZEVEDO; WAENY, 2001) é o registro que melhor abordou o assunto em, aproximadamente, 40 minutos de duração. Ali se buscou resgatar a memória da Psicologia esportiva no país, através de cenas e depoimentos, fazendo justiça a este pioneiro da Psicologia.

A Psicologia do Esporte, tanto nos EUA como na URSS e, também, no Brasil, se desenvolveu desde seus primórdios fora da Psicologia e dentro dos domínios da Educação Física ou das Ciências do Esporte (CRUZ, 1991; WEINBERG; GOULD, 2008). No Brasil, foi reconhecida como uma especialidade pelo Conselho Federal de Psicologia em dezembro de 2000 (RÚBIO, 2000). No entanto, após uma década, quase que nenhum curso brasileiro de graduação em Psicologia tem a Psicologia do Esporte em seu currículo. Por outro lado, praticamente todos os cursos de Educação Física apresentam esta disciplina em seus programas. Em decorrência disso, os principais estudiosos e pesquisadores brasileiros da Psicologia do Esporte têm vínculo de trabalho com as faculdades de Educação Física. Em que medida o relato histórico da Psicologia do Esporte no Brasil estaria mediado por essas contingências? Em que medida se poderia clarificar a passagem de João Carvalhaes pela Seleção Brasileira de Futebol de 1958 sem discutir a relação entre a Psicologia e as Ciências do Esporte?

Algumas evidências dessa problemática podem ser observadas em Argimon et al. (2006, p. 1) que, através de pesquisa empírica realizada no futebol profissional, concluíram que:

Os técnicos mostram-se ambivalentes em relação ao profissional da psicologia, sentindo sua prática ameaçada por esta intervenção. O psicólogo, nesse contexto, ainda não realiza uma efetiva inserção no meio esportivo, delimitando seu espaço e a importância de seu trabalho.

Da mesma forma, Epiphanio (1999, p. 72) se referindo aos problemas enfrentados pelo psicólogo do esporte, registrou a concorrência que o mesmo sofre no ambiente desportivo.

O mesmo também ocorre quando falamos de outros profissionais atuando como psicólogos do esporte, que não possuem a sensibilidade aos processos psíquicos, que apenas a formação em Psicologia garante. Identificar os conflitos de um atleta, ou de uma equipe esportiva, não é o mais difícil, mas saber promover um processo elaborativo requer aprofundamento psicológico, que a formação psicológica deve fornecer. 
Antes de promover certezas sobre nossa história, o presente texto procurou trazer provocações e dúvidas que emergiram de lacunas da trajetória de João Carvalhaes na Psicologia do Esporte brasileira. Estas incertezas poderão se constituir em futuros problemas de pesquisa para a construção de uma história da Psicologia do esporte no Brasil. A prática de Psicologia desportiva de João Carvalhaes teria efetivamente ocorrido antes que os EUA e a URSS? Quais os motivos que levaram João Carvalhaes a ser "convocado" para participar da comissão técnica da seleção brasileira de futebol de 1958 e qual a relação disso com os insucessos anteriores da equipe (1950 e 1954) e a cultura futebolística de preconceito e discriminação racial? Carvalhaes teria sido "bode expiatório" ou "boi-de-piranha"? Este texto pretende chamar a atenção para a ideia de que, no mínimo, essa parte da história da Psicologia esportiva brasileira talvez ainda não tenha sido "bem contada".

\section{Referências}

ARGIMON, I. DE L.; PALMA, C. C.; BOAZ, C.; DE LA ROSA, H. R.; DALDON, K. A.; NASCIMENTO, R. F. L. do. Técnicos de futebol e a prática da Psicologia no esporte. PSICOLOGIA. PT: O Portal dos Psicólogos, 2006. Disponível em: <http://www.psicologia.pt/artigos/>. Acesso em: 07 nov. 2009.

ASSAF, R. Tetra enterrou tese do "vulnerável". Jornal do Brasil: Esportes, $2001 . \quad$ Disponível em: <http://jbonline.terra.com.br//jb/papel/esportes/2001/06/13/joresp2 0010613007.html>. Acesso em: 19 mar. 2010.

BECKER JR, B. Manual de Psicologia do Esporte \& exercício. Porto Alegre: NOVAPROVA, 2000.

Uma análise crítica sobre a evolução da Psicologia do Esporte no Brasil. Revista Brasileira de Psicologia do Esporte, v. 0, p. 104-141, 2006.

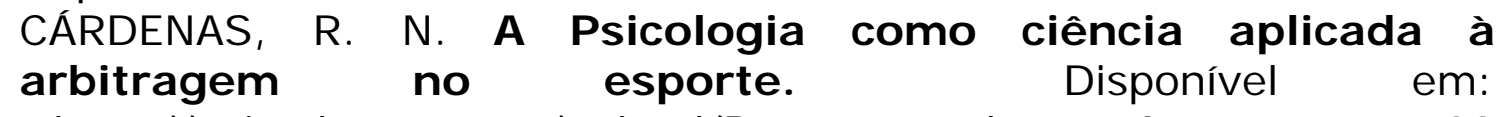
<http://psicodeporte.net/upload/Ramon_rte.doc>. Acesso em: 23 ago. 2008.

CARVALHAES, J. A Psicologia e o trabalho. Revista Brasileira de Estudos Pedagógicos, Brasília, v. 8, n. 22, p. 67-78, maio/jun. 1946.

- Novo Teste de Coordenação Motora. Arquivos Brasileiros de Psicotécnica, v. 7, n. 2, p. 15-21, jun. 1955.

Alguns fatores psicológicos da produtividade. Arquivos Brasileiros de Psicotécnica, ano 12, n. 1, p. 77-82, jan./mar.1960. 
Correlação entre o estado psicológico e o rendimento do atleta de futebol e consequente prognóstico. Arquivos Brasileiros de Psicologia Aplicada, v. 21, n. 3, p. 63-88, jul./set. 1969.

Teatro, Psicologia e prevenção de acidentes. Arquivos Brasileiros de Psicologia Aplicada, v. 22, n. 1, p. 95-110, jan./mar.1970.

Manual de destreza digital (TC). São Paulo: Vetor, 1970.

Sociometria e experimentação de dinâmica de grupo no

futebol. Arquivos Brasileiros de Psicologia Aplicada, v. 23, n. 1, p. 73-98, jan./mar. 1971.

- Considerações sobre a inteligência do atleta de futebol. Arquivos Brasileiros de Psicologia Aplicada, v. 23, n. 2, p. $97-$ 101, abr./jun. 1971.

. Um psicólogo no futebol: relatos e pesquisas. São Paulo: Éditora Esporte e Educação, 1974.

CARVALHO, C. A.; JACÓ-VILELA, A. M. Psicologia do Esporte no Brasil em dois tempos: uma história contada e uma história a ser contada. In: XV ENCONTRO NACIONAL DA ABRAPSO, 2009, Maceió. Anais de Trabalhos Completos. Maceió: 2009. p. 1-7.

CIAMPA, F. da C.; AZEVEDO, M. L. B.; WAENY, F. C. Pioneiro da Psicologia do Esporte: João Carvalhaes. [Filme-vídeo]. Produção: Mônica Leopardi B. de Azevedo e Maria Fernanda Costa Waeny. Direção: de Fernão da Costa Ciampa. São Paulo: Conselho Regional de Psicologia de São Paulo, 2001.

COSTA, H. C. B. V. A. Resgatando a memória dos pioneiros: João Carvalhaes. Boletim da Academia Paulista de Psicologia, v. 26, 3, p. 15-21, 2006.

COZAC, J. R. A Psicologia do Esporte: uma atualização teórica CEPPE. 04 mar. 2010.2 Disponível em: <http://www. ceppe.com.br/index.php/Psicologia-esportiva.html>.

Acesso em: 04 jun. 2011.

CRUZ, J. Historia de la Psicología del Deporte. In: RIERA, J.; CRUZ, J. (Eds.). Psicología del Deporte: aplicaciones y perspectivas. Barcelona: Ediciones Martínez Roca, S. A., 1991. p. 13-42.

DA SILVA, E. Formação da arbitragem. Revista Esportiva On-line Agora Esportes, Paraíba, abr. 2007. Disponível em: <http://www. agoraesportes. com. br/html/noticia. asp?not=28624>.

Acesso em: 04 jun. 2011.

EPHIPANIO, E. H. Psicologia do Esporte: apropriando a desapropriação. Psicologia: Ciência e Profissão, Brasília, v. 19, n. 3, p. 70-73, 1999.

FERNANDES, C. A cabeça do craque sob investigação. Segredos da Bola. Publicado em: 13 ago. 2009. Disponível em: <http://segredosdabola. wordpress.com/2009/08/13/a-cabeca-docraque-sob-investigacao-2/>. Acesso em: 03 jan. 2010. 
KELLOGG, C. E; MORTON, N. W. Revised Beta Examination. Personnel J ournal, v. 13, p. 94-100, 1934.

LEPIANI, G. Brasil é campeão. Revista Veja, junho, Edição Extra, 1958.

LIMA, J. G. de; AMORIM, R. Quem será o herói nacional? Revista Época Online 05. Jun. 2006, p. 11-33, Edição n. 420. Disponível em: <http://revistaepoca.globo.com/Revista/Epoca/0, ,EDG743775856-420,00-ESPECIAL+IEPOCA+ONLINE+NA+COPAI.html>. Acesso em: 04 jun. 2011.

LOURENÇO FILHO, M. B. A Psicologia no Brasil. Arquivos Brasileiros de Psicologia Aplicada. Rio de Janeiro, v. 23, n. 3, p. 41-53, set. 1971.

MANCEBO, D. Formação em Psicologia: gênese e primeiros desenvolvimentos. Mnemosine, v. 1, n. 0, p. 53-72, 2004.

MÁRIO FILHO. O negro no futebol brasileiro. Rio de Janeiro: Editora Mauad, 2003.

MARTINS, H. V. Uma revolução e um revolucionário? A Psicologia na época de Mira y Lopez. Mnemosine, v. 1, n. 0, p. 193-198, 2004.

MORRIS, T.; HACKFORT, D.; LIDOR, R. From pope to hope: the first twenty years of ISSP, 1998. Disponível em: <http://www.issponline.org/documents/History_of_ISSP.pdf>.

Acesso em: 05 jun. 2011.

PAES DE ALMEIDA, M. R. Prefácio. In: CARVALHAES, J. Um psicólogo no futebol: relatos e pesquisas. São Paulo: Editora Esporte e Educação, 1974. p. 11-12.

PENNA, A. G. Breve contribuição à história da psicologia aplicada ao trabalho no Rio de Janeiro. Mnemosine, v. 1, n. 0, p. 143-148, 2004.

PESSOTTI, I. Notas para uma História da Psicologia Brasileira. In: CONSELHO FEDERAL DE PSICOLOGIA (Org.). Quem é o psicólogo brasileiro? São Paulo: Edicon, 1988. p. 17-31.

PIZA, D. Meio Século de um Mito. Estadão de Hoje: Esportes. 2008. Disponível em: <http://www.estadao.com.br/estadaodehoje/20080420/not_imp1598 94,0.php>. Acesso em: 03 jan. 2010.

RIBEIRO DA SILVA, A. Observações sobre Psicologia aplicada ao futebol. Arquivos Brasileiros de Psicotécnica, ano 17, n. 3, p. 6772, jul./set. 1965.

Preparação psicológica. In: DA COSTA, L. (Coord.). Introdução à moderna ciência do treinamento desportivo. Brasília: Ministério da Educação e Cultura, 1968. p. 295-327.

RÚBIO, K. História e evolução da Psicologia do esporte. Revista Paulista de Educação Física, São Paulo, v. 6, n. 2, p. 73-78, 1992. Q Quem sou? De onde vim? Para onde vou? Rumos e necessidades da Psicologia do Esporte no Brasil. In: (Org.). 
Encontros e desencontros: descobrindo a Psicologia do esporte. São Paulo: Casa do Psicólogo, 2000. p. 123-132. . Origens e evolução da Psicologia do esporte no Brasil. Revista Bibliográfica de Geografia $Y$ Ciências Sociales, Barcelona, v. 7, n. 373, p. 31-37, 2002.

. Da Psicologia do esporte que temos à Psicologia do esporte que queremos. Revista Brasileira Psicologia do Esporte, v. 1, $\mathrm{n}$. 1, p. 1-13, 2007.

SAMULSKI, D. Psicologia do esporte. Barueri: Manole Ltda, 2002.

SARMENTO, C. E. A regra do jogo: uma história institucional da CBF/Coordenação Adelina Maria Novaes Cruz, Carlos Eduardo Sarmento e Juliana Lage Rodrigues. Rio de Janeiro: CPDOC, 2006.

URBINA, S. Fundamentos da testagem psicológica. Porto Alegre: ArtMed, 2007.

VALDÉS CASAL, H. M. Fatos e reflexões sobre a História da Psicologia do esporte. In: BRANDÃO, M. R. F.; MACHADO, A. A. (Eds.). Coleção Psicologia do Esporte: v. 1: teoria e aplicação. São Paulo: Atheneu, 2007. p. 1-29.

WEINBERG, R. S.; GOULD, D. Fundamentos da Psicologia do esporte e do exercício. Porto Alegre: ArtMed, 2008.

WEINBERG, R. S.; RICHARDSON, P. A. Psychology of officiating. Champaign: Leisure Press, 1990.

\section{Endereço para correspondência}

José Augusto Evangelho Hernandez

Rua São Francisco Xavier, 524, bloco F, $10^{\circ}$ andar, Secretaria da Graduação em Psicologia da UERJ, CEP 22550-013, Rio de J aneiro - RJ.

Endereço eletrônico: hernandez.uerj@gmail.com

Recebido em: 21/06/2011

Reformulado em: 29/08/2011

Aceito para publicação em: 06/09/2011

Acompanhamento do processo editorial: Ana Maria Jacó Vilela

\section{Notas}

* Professor Adjunto do Instituto de Psicologia - UERJ .

${ }^{1}$ SCHNEIDER, E. Depoimento. In: FÁVERO, Maria de Lourdes de Albuquerque (coord.). Faculdade Nacional de Filosofia: depoimentos. Rio de Janeiro: Editora UFRJ , 1992. 